\title{
Examining volatility spillover between Asian countries' stock markets
}

\author{
Khalil Jebran $^{1^{*}}$ and Amjad lqbal ${ }^{2}$
}

\author{
* Correspondence: \\ khaliljebranuom@gmail.com \\ ${ }^{1}$ Department of Management \\ Studies, University of Malakand, \\ Chakdara, Pakistan \\ Full list of author information is \\ available at the end of the article
}

\begin{abstract}
Background: This study examined the volatility spillover effects between the stock markets of Asian countries, i.e., Pakistan, India, Sri Lanka, China, Japan, and Hong Kong.

Methods: The daily data was considered from the period 4 January 1999 to 1 January 2014, consisting five trading days from Monday to Friday. The volatility spillover between stock markets was captured by using the generalized autoregressive conditional heteroskedasticity (GARCH) model.

Results: The empirical analyses show evidence of significant bidirectional spillover of return and volatility between China and Japan. The results also show significant bidirectional volatility transmission between the equity markets of the following countries: Hong Kong and Sri Lanka, China and Sri Lanka. The significant unidirectional transmissions of stock market volatility are found to be flowing from India to China, Sri Lanka to Japan, Pakistan to Sri Lanka, and Hong Kong to India and Japan.
\end{abstract}

Conclusions: These results are important for economic policy makers in order to safeguard the financial sector from international financial shocks. The investors can use this information for making efficient portfolio which will reduce their risk and enhance their returns.

Keywords: Volatility spillover, Asian countries, GARCH model, Time series analyses

\section{Springer}

\section{Background}

Liberalization opened different sets of opportunities to investors, which provided investors an opportunity to select and manage different portfolios around the globe. The internationalization of equity markets gained considerable attentions from investors all over the world. Investors began to invest in different equity markets wherever they can earn more benefits. The removal of investment barriers to equity markets not only enhanced the returns of investors but also became the cause of integration of different equity markets. The flow of financial crises between different markets is one of the foremost causes of integrations of markets. The knowledge about spillover of financial information from one market to another gained a considerable attention over the last few decades. The main focus of the researchers is to provide the information about integration about markets because two integrated markets will not provide the benefits of portfolio diversification (Jebran 2014).

Numerous studies examined the spillover effects of volatility between different equity markets. Most of the researchers have studied developed equity markets for volatility

(C) 2016 Jebran and Iqbal. Open Access This article is distributed under the terms of the Creative Commons Attribution 4.0 International License (http://creativecommons.org/licenses/by/4.0/), which permits unrestricted use, distribution, and reproduction in any medium, provided you give appropriate credit to the original author(s) and the source, provide a link to the Creative Commons license, and indicate if changes were made. 
spillover effects; however, there are also studies which examined developing as well as emerging equity markets. The various studies carried out for developed equity markets include studies like Hu et al. (1997), Chou et al. (1999), Ng (2000), Baele (2002), Wagner and Szimayer (2004), Harris and Pisedtasalasai (2006), Diebold and Yilmaz (2009), and Xiao and Dhesi (2010). The studies on developing equity markets include Mukherjee and Mishra (2010), Joshi (2011), Choo et al. (2011), and Sakthivel and Kamaiah (2011). There are also studies that examined emerging equity market integrations, see for example, Wang et al. (2005), Worthington and Higgs (2004), Li and Majerowska (2008), and Beirne et al. (2009). These studies provide valuable insights about integration between equity markets and provide investors effective investment opportunities regarding portfolios.

Markowitz (1952) laid the foundation of portfolio theory. He provided the concept of portfolio diversification. According to him, investments should be made on the basis of risk and return relationship. People should prefer those investments which provide maximum benefit at a given level of risk or should prefer low risk at a given level of return. According to portfolio theory, investment should be made in non-correlated assets. This reveals that if there is no correlation between assets, then the shock that arises in one asset may not transmit to other assets and vice versa. In this aspect, the risk of investment is minimized and return is maximized. So careful selection of assets should be made in this regard to minimize the risk and maximize the return of portfolios.

The foundation of portfolio theory gained a considerable attention from investors to know about the integration between different equity markets around the globe. This motivated many investors and researchers to explore the integration of different equity markets. The knowledge of integration would help investors to prevent themselves from market imperfections. If the markets are integrated in terms of spillover of volatility, so one market crises will be transferred to other markets (Baele 2002; Choo et al. 2011). The other aspect regarding the integration of markets is that it also plays a key role for determining the price of different securities. The investor is willing to pay a high price for non-integrated securities rather than correlated assets (Glezakos et al. 2007).

The importance of unveiling the association of equity markets has motivated this study to know about the relationship between different equity markets. This study has been undertaken to study the volatility spillover effects between Asian countries. The aim behind using Asian countries is to provide insights to investors regarding their geographical equity markets. The Asian countries included in this study are taken from South and East Asia. This study considered three countries from South Asia and three from East Asia. The countries taken from South Asia are Sri Lanka, India, and Pakistan. The countries considered from East Asia are Japan, Hong Kong, and China. Karachi Stock Exchange (KSE) is the major market in Pakistan and is considered for this study. The Bombay Stock Exchange (BSE) has been selected from India. The Colombo Stock Exchange (CSE) is selected from Sri Lanka. The Shanghai Stock Exchange (SSE) is selected from China. The Hang Seng Stock Exchange (HSSE) is selected from Hong Kong. The Nikkei 225 (Nikkei) is considered from Japan in this study. The novelty of this paper is that it is using daily data which is considered to give more spurious results than weekly and monthly data. Furthermore, this study considered a 15-year period for the purpose of long-term analyses. This study will add to the literature of Asian countries. This study also constitutes a sample of diverse mix countries and will also add to the literature of diverse mix Asian countries. 
This study will provide benefits to investors, as the information of this study will provide them knowledge about the integration of markets which will help them in making portfolio decisions.

The rest of the paper is organized as follows. The second part discusses the literature review. The third part shows methods and data description. The fourth section discusses empirical results. The fifth part is about conclusion and policy implication.

\section{Review of literature}

The finance literature provides numerous studies which provide information about volatility spillover effects between different stock markets. The knowledge of how information is transmitted from one market to another is the prime focus of many domestic and foreign investors for the investment decision-making in different markets. Most of the studies have been carried out to study developed equity markets; however, there are also studies analyzing developing and emerging markets. The literature can be divided into studies that have been undertaken to study developed, developing, and emerging equity markets. The studies on developed equity markets include $\mathrm{Hu}$ et al. (1997), Chou et al. (1999), Ng 2000, Baele (2002), Wagner and Szimayer (2004), Harris and Pisedtasalasai (2006), Diebold and Yilmaz (2009), and Xiao and Dhesi (2010). Hu et al. (1997) studied four emerging markets named Shenzhen, Shanghai, Hong Kong, and Taiwan with the developed equity market in the USA and Japan. Their analyses were based on daily data from period 5 October 1992 to 15 February 1996. By applying the causality in variance test, they found evidence of transmission of volatility among Hong Kong and US markets. Chou et al. (1999) provided evidence of spillover effect of volatility between US and Taiwan markets. The analyses were made using Engle and Kroner M-generalized autoregressive conditional heteroskedasticity (GARCH) model. They used various types of data in examining volatility: closed to open and open to closed data rather than simply using daily data. Their analyses indicate the transmission of both return and variance between Taiwan and USA. Ng (2000) examined the transmission of volatility from Japan and US equity markets to six Pacific Basin stock markets (Thailand, Korea, Hong Kong, Malaysia, Singapore, and Taiwan). By taking the weekly data of stock returns, he analyzed by using ARCH family framework. The empirical analyses of the study provide evidence of spillover of volatility from Japan and USA to many equity markets of the Pacific Basin. Baele (2002) extended the literature of flow of volatility of the US and European Union markets with selected 13 markets of Europe. He has taken weekly data of stock returns and analyzed by using the GARCH and BEKK model. He found increasing tendency of shocks for many markets during 1990. The results further provide evidence of shock transmission from the US market to Switzerland, UK, and Sweden. Wagner and Szimayer (2004) studied the established equity market of Germany and USA in examining volatility transmission. They have considered daily data from 1992 to 2002. Their analyses reveal statistically significant spillover effects of equity markets, but the tendency was mostly related to country specifics. They concluded that the shock spillover shows robustness in the crises period. Harris and Pisedtasalasai (2006) empirically studied the mean and volatility transmission for the small and large stocks in the UK. The daily data taken from January 1986 to December 2002 is converted into continuous compounded return for the indices of 
FTSE small caps, FTSE 250, and FTSE 100. The empirical analyses are undertaken by using the GARCH model. By applying the model, they found statistically significant transmission of volatility for both the small caps and large caps of the UK. They finally concluded that the shocks are mostly flowing from larger caps to smaller caps of the UK market. Diebold and Yilmaz (2009) extended the literature for seven developed equity markets (France, Germany, Japan, USA, Hong Kong, and UK) with 12 emerging markets (South Korea, Chile, Argentina, Taiwan, Singapore, Philippines, Thailand, Brazil, South Korea, Argentina, Mexico, and Malaysia). They have done a novel work in examining volatility transmission by taking data of both before and after Asian financial crises period. The VAR model is applied in examining volatility transmission. Their results reveal no current trend in return spillover but show robustness with time. However, they found clear robustness of volatility transmission with time. They concluded integration of many markets. Xiao and Dhesi (2010) examined transmission of volatility for four indices (FTSE 100, S \& P 500, DAX and CAC) from the period 5 January 2004 to 1 October 2009. They used two different multivariate models, BEKK and DCC models, and found evidence of statistically significant volatility transmission between the European and US markets. Their results show evidence of spillover of shock from the US to all other selected equity markets.

The studies on developing equity markets include studies, for example, Mukherjee and Mishra (2010), Joshi (2011), Choo et al. (2011), and Sakthivel and Kamaiah (2011). Mukherjee and Mishra (2010) empirically examined volatility transmission of equity market of India with 12 selected equity markets (China, Malaysia, Sri Lanka, Thailand, Indonesia, Pakistan, Malaysia, Korea, Hong Kong, Sri Lanka, Taiwan, and Japan). Their observations consist of intraday stock price from July 1998 to April 2008. By applying the GARCH model, they found evidence of bidirectional return spillover between India and all selected markets except Sri Lanka. Joshi (2011) empirically examined the spillover of return and volatility between Asian countries (Korea, China, India, Indonesia, Hong Kong, and Japan). By applying the GARCH BEKK model, he found bidirectional return spillover in the following markets: Indonesia and China, Korea and Japan, India and Hong Kong, and Hong Kong and Korea. Choo et al. (2011) examined volatility transmission between larger and smaller stocks of Malaysian equity market. By using daily data from April 1992 to September 2005, they employed the GJRGARCH model in examining volatility transmission. Their analyses show evidence of bidirectional spillover of return for larger and smaller stocks. Sakthivel and Kamaiah (2011) examined co-movement and transmission of volatility between markets of India, Australia, USA, UK, and Japan. By using the GARCH model, they found bidirectional spillover of volatility from India and US equity market. They also found unidirectional transmission of shocks from the UK and Japan to India.

The studies on emerging equity markets include studies like Wang et al. (2005), Worthington and Higgs (2004), Li and Majerowska (2008), and Beirne et al. (2009). Wang et al. (2005) used the EGARCH model in examining the volatility transmission from established equity markets of Japan and USA to newly emerged capital markets of Asia. Their empirical analyses show evidence of both return and shock transmission from established markets to emerging capital markets of Asia. Worthington and Higgs (2004) studied the emerging market of Asia for cross-border transmission of volatility. They used the GARCH model for investigating spillover effects. They found statistically 
significant spillover of volatility from Japan capital market to newly emerged markets of Indonesia, Korea, and Hong Kong. Li and Majerowska (2008) empirically investigated emerging market of Budapest Stock Exchange and Warsaw Stock Exchange in comparison with USA and Frankfurt. The daily data is examined through the BEKK GARCH model. Their analyses reveal clear evidence of transmission of volatility from US and DAX capital markets to Budapest and Warsaw equity market. Beirne et al. (2009) examined newly emerged markets with established markets for flow of shocks from one market to another. The data ranges from 1990 to 2008 for 41 newly emerged markets. By applying the tri-variate GARCH model, they found clear evidence of flow of shocks from established markets to emerging markets.

Based on the discussed literature, we develop the following hypothesis for this study.

H0: There is no volatility spillover between Asian countries' stock markets

H1a: There is bidirectional volatility spillover between Asian countries' stock markets

H1b: There is unidirectional volatility spillover between Asian countries' stock markets

\section{Methods}

This study is using time series data for the period 4 January 1999 to 1 January 2014. The period of study is of 15 years aiming for comprehensive analyses. The data for the selected equity markets of Asian countries is obtained from Yahoo finance.com. The observations consist of stock price indices which consist of daily closing stock indices. The closing stock price indices consist of five working days from Monday to Friday. As this study considered daily data, so there were missing observations in many stock market data. The missing values have been calculated by using interpolation method. This is done in order to capture daily volatility spillover. The data for stock indices has been matched with each other in terms of dates in order to have daily analyses. This study considered Asian countries' stock markets. This study has taken three countries from South Asia and three from East Asia. The countries selected from South Asia are India, Sri Lanka, and Pakistan. The countries taken from East Asia are Japan, Hong Kong, and China. Karachi Stock Exchange (KSE) is the major market in Pakistan and is considered in this study. The Bombay Stock Exchange (BSE) has been selected from India. The Colombo Stock Exchange (CSE) is selected from Sri Lanka. The Shanghai Stock Exchange (SSE) is selected from China. The Hang Seng Stock Exchange (HSSE) is selected from Hong Kong. The Nikkei 225 (Nikkei) is considered from Japan in this study.

As this study considered time series data, so it is necessary to analyze the stationarity of the underlying variables. The most widely methods used to check stationarity are Dickey and Fuller (1979) (ADF) and Phillips and Perron (1988) (PP) test. Dickey and Fuller (1979) test is used given the below regression model.

$$
\Delta Y_{t}=\beta_{0}+\sigma Y_{t-1}+a_{i} \sum_{i=1}^{m} \Delta Y_{t-1}+\mu_{t}
$$

where $\Delta$ shows differences, $\alpha, \beta$, and $\sigma$ are coefficients, and $Y$ is a variable to be estimated. Phillips and Perron (1988) test is based on the first-order autoregressive model on the following equation. 


$$
\Delta Y t=\alpha_{0}+\beta Y_{t-1}+\mu_{t}
$$

where $\alpha$ is a coefficient, $\Delta$ represents differences, $\beta$ is slope, and $Y$ is a variable to be estimated.

The volatility spillover between the Asian countries' stock markets is examined by using GARCH. The GARCH analyses can be carried out on the data which has autocorrelation and heteroskedasticity issues. Before estimating the GARCH model, the $\mathrm{ARCH}$ effect has been analyzed in data in order to know about the presence of heteroskedasticity and autocorrelation data in variables. Table 3 shows the results of ARCH effect in the underlying variables of the study. The probability of chi-square is checked for analyzing the ARCH effect which shows significant ARCH effect in all stock market indices. The GARCH model of this study has been represented in Eqs. (3) and (4). Equation (3) shows the mean equation and Eq. (4) shows the variance equation. Equation (4) is the volatility spillover equation to be carried out. First, we have estimated a separate model of GARCH for each series and after that generated volatility residual series from that specific model for each stock market. We have used squared volatility residuals in our analyses because in GARCH model, volatility is assumed to be positive. The generated volatility residual series has been used as a proxy for shock to each stock market indices which has been used in Eq. (4).

$$
\begin{aligned}
& Y_{t}=c+\gamma Y_{t-1}+\omega_{t-1}+\varepsilon_{t} \\
& h_{t}=\alpha_{0}+\beta_{1} \varepsilon_{t-1}^{2}+\alpha_{1} h_{t-1}+\delta\left(\text { squared residual }_{\text {stock indices }}\right)
\end{aligned}
$$

Equation (3) is the mean equation which examines the return spillover from one market to another market, while the Eq. (4) is the volatility spillover equation that measures the volatility spillover from one market to another. In Eq. (3), $R_{t}$ represents the return of stock indices, the parameter $\gamma$ measures the effect of lagged return on the stock indices, and the parameter $\omega$ measures the effect of lagged return on the underlying stock market. In simple words, it measures the return spillover from the underlying market. In Eq. (4), $\alpha_{1} \geq 0, \beta_{1} \geq 0$, and $\alpha_{0}>0 ; h_{t}$ represents conditional variance of equity markets that is a mean function; $\alpha_{0}$ volatility news of previous period is examined as the first difference of residual square from mean equation $\left(\varepsilon_{t-1}^{2}\right) ; h_{t-1}$ is previous period's estimated variance. In Eq. (4), the parameter $\delta$ measures the volatility

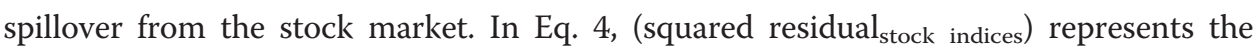
generated squared volatility residuals, which has been generated from a separate GARCH model for each stock market.

\section{Empirical results}

In the preliminary step, the behavior of the data has been analyzed by using descriptive statistics. Table 1 shows the analyses of descriptive statistics for the selected stock markets. The analyses show evidence that the highest mean daily return between the selected equity markets is given by the stock market of Pakistan that is $0.08 \%$, while the minimum mean daily return for the period of study is shown by Japan Stock Exchange that is $0.0049 \%$. Furthermore, the descriptive statistics shows that maximum mean standard deviation is represented by the stock market of India that is $1.56 \%$, while the minimum mean standard deviation of $1.12 \%$ is represented by the equity market of Sri Lanka. Furthermore, the analyses show that all the stock market indices are negatively 
Table 1 Summary statistics

\begin{tabular}{llllllll}
\hline & Mean & Maximum & Minimum & Std. dev. & Skewness & Kurtosis & Jarque-Bera \\
\hline India & 0.000489 & 0.159943 & -0.11809 & 0.015626 & -0.11385 & 9.713559 & 7355.167 \\
Sri Lanka & 0.000592 & 0.116124 & -0.13906 & 0.011217 & -0.34435 & 23.37271 & $67,730.02$ \\
Hong Kong & 0.000221 & 0.134068 & -0.13582 & 0.015336 & -0.07551 & 10.93031 & $10,254.75$ \\
Pakistan & 0.000844 & 0.082547 & -0.07741 & 0.013991 & -0.34711 & 6.099103 & 1644.079 \\
Japan & $4.92 \mathrm{E}-05$ & 0.094941 & -0.12111 & 0.01473 & -0.66144 & 8.868493 & 5898.844 \\
China & 0.00016 & 0.094008 & -0.09256 & 0.015489 & -0.02587 & 7.578448 & 3417.272 \\
\hline
\end{tabular}

Source: authors' formation

skewed. The Jarque-Bera statistics is significant in all stock market indices. The descriptive statistics shows that all the stock indices data are not normally distributed.

Figure 1 represents the time plot of all the selected stock market indices of the countries. The graph illustrates that most of the stock market indices are showing common trends. The stock indices are showing declining trend after 2007 which was due to global financial crises. Figure 2 represents the graphical representation of the stock index return data for the selected period. The figure elaborates that all stock indices are more volatile in the selected period. The volatility clustering in all indices is found more after the 2007 crises period.

The second step is to analyze the stationarity of all the selected stock market indices of the study. The stationarity of the data is analyzed by employing unit root analyses. The Dickey and Fuller (1979) (ADF) and Phillips and Perron (1988) (PP) tests were employed to examine the order of stationarity of the data. Table 2 shows the empirical results of unit root analyses that have been carried out on the natural logarithms of stock price index of all markets. The analyses show clear evidence of non-stationarity of all underlying variable on a level while stationarity on the first lag of all variables. The ADF and PP tests represent similar results of stationarity.

The transmission of volatility spillover is aimed to be examined by employing the GARCH model. The observations of the study are converted into continuously compounding returns for the purpose of capturing conditional variance of stochastic components of the returns. The GARCH model is related to ARCH family framework. The assumption of the ARCH family is that there must be heteroskedasticity and autocorrelation problem in a data set. In other words, ARCH effect should exist in a data set. In this aspect, $\mathrm{ARCH}$ effect is examined by employing autoregressive model. The variable is converted to first lag, and then ARCH test is applied to examine ARCH effect by checking probability of chi-square. The results of autoregressive model are shown in

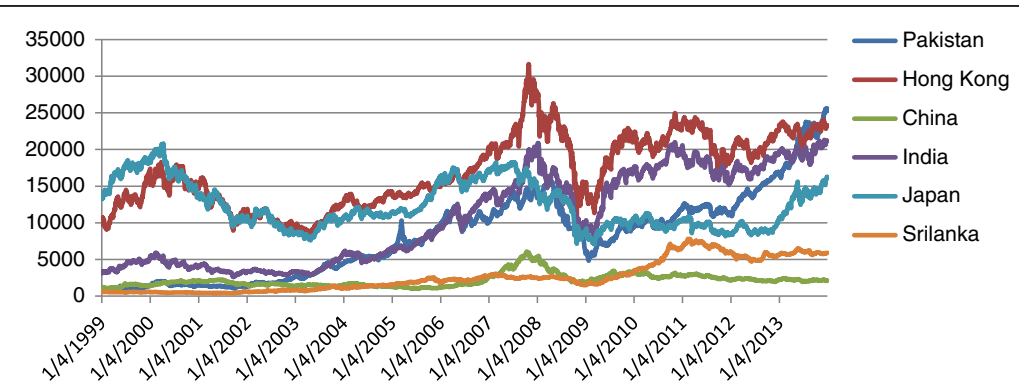

Fig. 1 Stock market index. Source: authors' formation 


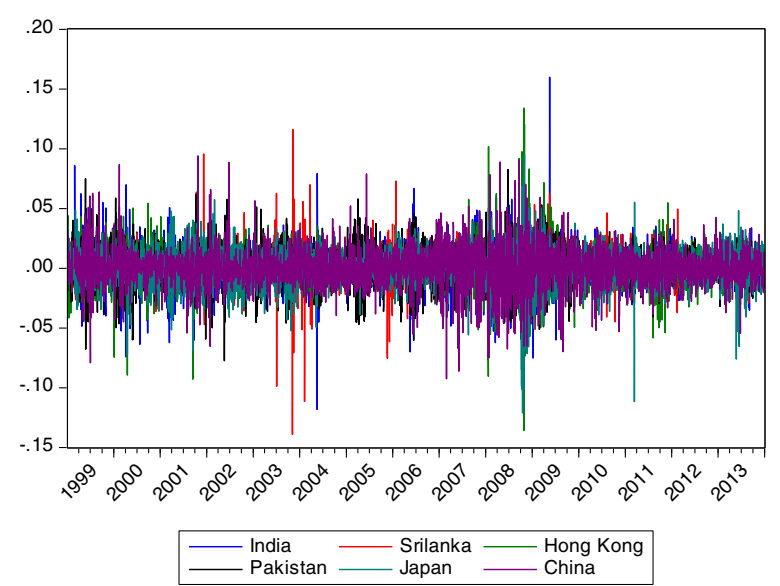

Fig. 2 Stock index returns. Source: authors' formation

Table 3. The result shows the presence of ARCH effect in all stock markets. This confirms that GARCH model can be applied, as there exists a problem of both heteroskedasticity and autocorrelation in all the underlying data sets.

The analyses of the mean equation are represented in Table 4. The mean equation shows the results of return spillover between the selected stock indices. The analyses show statistically significant first lag own return spillover for equity market of India, Sri Lanka, Pakistan, and Japan, which imply that they are dependent on their own first lag. The own lag return effect of the stock market of Hong Kong and China is insignificant, which points to the evidence that these market returns do not depend on their own lag return. The bidirectional return spillover has been found between the stock markets of China and Japan. The bidirectional spillover between China and Japan represents that the returns of these markets are dependent on each other. Furthermore, the results show that China and Japan equity markets negatively affect the returns of each other. The results show no evidence of any other bidirectional return transmission between other selected equity markets. The results reveal unidirectional return spillover from

Table 2 Unit root results

\begin{tabular}{llllll}
\hline & \multicolumn{1}{l}{ ADF } & & \multicolumn{1}{l}{ PP } \\
\cline { 2 - 3 } \cline { 5 - 6 } Variables & Level & 1st diff. & & Level & 1st diff. \\
\hline India & -0.934554 & $-57.84548^{* *}$ & & -0.926896 & $-57.72980^{* *}$ \\
Sri Lanka & -0.393679 & $-40.83287^{* *}$ & & -0.446672 & $-50.11421^{* *}$ \\
Hong Kong & -1.836501 & $-62.70618^{* *}$ & & -1.836588 & $-62.70621^{* *}$ \\
Pakistan & -1.154962 & $-55.91908^{* *}$ & & -1.117635 & $-57.72733^{* *}$ \\
Japan & -1.662088 & $-62.97833^{* *}$ & & -1.585209 & $-63.04025^{* *}$ \\
China & -1.782500 & $-62.37812^{* *}$ & & -1.814469 & $-62.41755^{* *}$ \\
Critical values & & & & \\
$1 \%$ & -3.431837 & & & \\
$5 \%$ & -2.862082 & & & \\
$10 \%$ & -2.567102 & & & \\
\hline
\end{tabular}

Source: authors' formation

ADF Dickey and Fuller (1979) test of stationarity, PP Phillips and Perron (1988) test of stationarity ${ }^{* *} p<1 \%$ 
Table $3 \mathrm{ARCH}$ test

\begin{tabular}{llll}
\hline Variables & Constant & AR(1) & ARCH test \\
\hline Pakistan & $0.075523(0.00)$ & $0.111300(0.00)$ & $384.3693(0.00)$ \\
China & $0.016119(0.51)$ & $0.002308(0.88)$ & $87.42359(0.00)$ \\
India & $0.044887(0.07)$ & $0.077620(0.00)$ & $148.1162(0.00)$ \\
Japan & $0.005308(0.82)$ & $-0.007162(0.65)$ & $255.4044(0.00)$ \\
Hong Kong & $0.021946(0.37)$ & $-0.002907(0.85)$ & $461.4526(0.00)$ \\
Sri Lanka & $0.046225(0.00)$ & $0.223677(0.00)$ & $354.0241(0.00)$ \\
\hline
\end{tabular}

Probabilities are shown in parenthesis. AR(1) is the first difference of the computed variables. ARCH test is carried out to know about ARCH effect. Source: authors' formation

Sri Lanka to Indian stock market. The results reveal that Sri Lankan equity market enhances the returns of Indian equity market. Furthermore, the results show that there is unidirectional return spillover from equity market of China to Hong Kong and Pakistan equity markets, respectively. The results reveal that the stock market of China adversely affects the returns of Hong Kong while positively affects the returns of Pakistan equity market. Furthermore, the results imply that the stock market of India positively affects the returns of Hong Kong and Japan equity markets. The results show that Hong Kong stock market adversely affects the returns of Pakistan stock market. Overall, the magnitude of returns spillover was found greater in the case of India to Japan (0.1365) equity market while lowest (0.0147) in the case of Sri Lanka to Indian stock market.

The analyses of volatility spillover are represented in Table 5 . The analyses have been estimated separately for each market taking as a dependent variable, and all the other stock market volatility has been allowed to be examined for shock spillover. The volatility series has been created for each market and has been used as a proxy for shock spillover to other markets. The analyses show evidence of own market volatility

Table 4 Mean equation results

\begin{tabular}{lllllll}
\hline DV $\longrightarrow$ & India & Sri Lanka & Hong Kong & Pakistan & Japan & China \\
\hline $\mathrm{C}$ & $0.0009^{* *}$ & 0.0002 & 0.0001 & $0.0012^{* *}$ & 0.0001 & -0.0002 \\
& $(3.83 \mathrm{E}-05)$ & $(0.0003)$ & $(0.0004)$ & $(0.0003)$ & $(0.0004)$ & $(0.0004)$ \\
India $(-1)$ & $0.0942^{* *}$ & 0.0462 & $0.1234^{* *}$ & 0.0154 & $0.1365^{* *}$ & -0.0270 \\
& $(0.0052)$ & $(0.0261)$ & $(0.0276)$ & $(0.0199)$ & $(0.0271)$ & $(0.0291)$ \\
Sri Lanka (-1) & $0.0147^{* *}$ & $0.2259^{* *}$ & 0.0048 & 0.0289 & 0.0173 & 0.0112 \\
& $(0.0035)$ & $(0.0285)$ & $(0.0161)$ & $(0.0281)$ & $(0.0232)$ & $(0.0098)$ \\
Hong Kong (-1) & -0.0019 & -0.0068 & -0.0068 & $-0.0508^{*}$ & 0.0488 & 0.0330 \\
& $(0.0045)$ & $(0.0279)$ & $(0.0395)$ & $(0.0254)$ & $(0.0364)$ & $(0.0306)$ \\
Pakistan $(-1)$ & 0.0060 & 0.0018 & 0.0209 & $0.1295^{* *}$ & 0.0137 & -0.0164 \\
& $(0.0033)$ & $(0.0186)$ & $(0.0280)$ & $(0.0196)$ & $(0.0281)$ & $(0.0273)$ \\
Japan $(-1)$ & 0.0072 & 0.0089 & -0.0301 & -0.0101 & $-0.0770^{*}$ & $-0.0374^{*}$ \\
& $(0.0037)$ & $(0.0261)$ & $(0.0352)$ & $(0.0261)$ & $(0.0371)$ & $(0.0153)$ \\
China $(-1)$ & -0.0035 & -0.0137 & $-0.0717^{*}$ & $0.0509^{*}$ & $-0.0663^{*}$ & -0.0241 \\
& $(0.0029)$ & $(0.0255)$ & $(0.0284)$ & $(0.0200)$ & $(0.0260)$ & $(0.0307)$ \\
\hline
\end{tabular}

The figures in parenthesis are standard errors. India (-1) represents returns spillover from stock market of India. Sri Lanka $(-1)$ represents returns spillover from stock market of Sri Lanka. Hong Kong $(-1)$ represents returns spillover from stock market of Hong Kong. Pakistan ( -1$)$ represents returns spillover from stock market of Pakistan. Japan $(-1)$ represents returns spillover from stock market of Japan. China $(-1)$ represents returns spillover from stock market of China. Source: authors' formation ${ }^{*} p<5 \% ;{ }^{* *} p<1 \%$ 
Table 5 Variance equation results

\begin{tabular}{lllllll}
\hline DV $\longrightarrow$ & India & Sri Lanka & Hong Kong & Pakistan & Japan & China \\
\hline$a_{0}$ & $-7.77 \mathrm{E}-08$ & $0.0001^{* *}$ & $0.0001^{* *}$ & $0.0001^{* *}$ & $0.0001^{* *}$ & $0.0001^{* *}$ \\
& $(9.35 \mathrm{E}-08)$ & $(1.35 \mathrm{E}-05)$ & $(3.73 \mathrm{E}-05)$ & $(5.08 \mathrm{E}-05)$ & $(1.68 \mathrm{E}-05)$ & $(1.51 \mathrm{E}-05)$ \\
$\beta_{1} \varepsilon_{t-1}^{2}$ & $-0.1831^{* *}$ & $0.1443^{* *}$ & $0.1112^{* *}$ & 0.0509 & $0.1180^{* *}$ & $0.0972^{* *}$ \\
& $(0.0293)$ & $(0.0211)$ & $(0.0312)$ & $(0.0754)$ & $(0.0319)$ & $(0.0254)$ \\
$a_{1} h_{t-1}$ & $0.4162^{* *}$ & $0.5485^{* *}$ & $0.5234^{* *}$ & -0.0536 & $0.5295^{* *}$ & $0.4699^{* *}$ \\
& $(0.0617)$ & $(0.0570)$ & $(0.0994)$ & $(0.3326)$ & $(0.0527)$ & $(0.0219)$ \\
RSD_India & $0.4640^{* *}$ & -0.0001 & -0.0036 & -0.0052 & -0.0079 & $-0.0104^{* *}$ \\
& 0.185 & $(0.0019)$ & $(0.0136)$ & $(0.0031)$ & $(0.0046)$ & $(0.0008)$ \\
RSD_Sri Lanka & 0.0003 & $0.0127^{* *}$ & $-0.0200^{* *}$ & 0.0067 & $-0.0172^{* *}$ & $-0.0209^{* *}$ \\
& $(0.0005)$ & $(0.0022)$ & $(0.0029)$ & $(0.0013)$ & $(0.0024)$ & $(0.0011)$ \\
RSD_HongKong & $0.0051^{* *}$ & $-0.0061^{*}$ & $0.0235^{*}$ & -0.0004 & 0.0029 & 0.0039 \\
& $(0.0017)$ & $(0.0028)$ & $(0.0091)$ & $(0.0049)$ & $(0.0082)$ & $(0.0084)$ \\
RSD_Pakistan & 0.0003 & $-0.0244^{* *}$ & $-0.0411^{* *}$ & $0.2073^{* *}$ & $-0.0398^{* *}$ & -0.0219 \\
& $(0.0006)$ & $(0.0029)$ & $(0.0036)$ & $(0.0195)$ & $(0.0061)$ & $(0.0154)$ \\
RSD_Japan & $-7.93 \mathrm{E}-05$ & -0.0055 & 0.0021 & -0.0047 & $0.0193^{*}$ & $-0.0098^{* *}$ \\
& $(0.0002)$ & $(0.0040)$ & $(0.0132)$ & $(0.0055)$ & $(0.0087)$ & $(0.0104)$ \\
RSD_China & $9.71 \mathrm{E}-06$ & $-0.0159^{* *}$ & -0.0119 & -0.0037 & $-0.0229^{* *}$ & $0.0489^{* *}$ \\
& $(0.0004)$ & $(0.0024)$ & $(0.0086)$ & $(0.0085)$ & $(0.0082)$ & $(0.0070)$
\end{tabular}

The figures in parenthesis are standard errors. DV is the dependent variable used when the model is estimated. RSD_Pakistan represents volatility spillover from stock market of Pakistan. RSD_Sri Lanka represents volatility spillover from stock market of Sri Lanka. RSD_HongKong represents volatility spillover from stock market of Hong Kong. RSD_India represents volatility spillover from stock market of India. RSD_Japan represents volatility spillover from stock market of Japan. RSD_China represents volatility spillover from stock market of China. From top to down is the estimated model for a single market. Source: authors' formation

${ }^{*} p<5 \%$; ${ }^{* *} p<1 \%$

transmission in all selected stock indices. The magnitude of own market spillover of volatility is found to be highest in the case of the stock market of India (0.46) while lowest for the stock market of Sri Lanka (0.012).

\section{H0: no volatility spillover between Asian countries' stock markets}

The results reveal that the stock market of India shows no evidence of volatility spillover to the stock markets of Sri Lanka, Hong Kong, Pakistan, and Japan, respectively. Furthermore, the results reveal no volatility spillover from the stock market of Sri Lanka to Pakistan and India. The results also show that the stock market of Hong Kong shows no evidence of volatility transmission to the stock market of Pakistan, Japan, and China. The results reveal no volatility spillover from Pakistan stock market to the equity markets of India and China. Furthermore, the results show no volatility spillover from Japan to the stock markets of India, Sri Lanka, Hong Kong, and Pakistan. Moreover, the results show no evidence of volatility spillover from the stock market of China to India, Pakistan, and Hong Kong. The analyses also point to the evidence that the selected Asian equity markets have no volatility spillover to the stock market of Pakistan. This result points to the evidence that the equity markets of selected Asian countries remains independent to the shocks of their respective regional geographical equity markets. The absence of volatility spillover between the stock markets serves an important role in portfolio diversification. The no 
volatility spillover between the markets represents that these markets offer diversification opportunities to investors. The institutional and individual investors can invest in these non-correlated markets and can minimize their risk and enhance their portfolio returns.

\section{H1a: bidirectional volatility spillover between Asian countries' stock markets}

The results show significant bidirectional volatility between Hong Kong and Sri Lanka equity markets, but the persistence of volatility spillover is found larger in the case of Sri Lanka. Furthermore, the results show that Sri Lanka and China equity markets have bidirectional volatility spillover. Moreover, there are bidirectional linkages between China and Japan. The significant bidirectional spillovers of volatility imply that the shock in one market is responsible to bring changes in the other market volatility and vice versa. The bidirectional volatility spillover between equity markets represents that these markets are integrated. Furthermore, the integration of these markets also points to the evidence that there are less diversification benefits for investors in these markets. The economic integration between the selected markets might be due to the geographical location which allows investors to allocate their assets in the selected market which decreases their transaction cost. The low restrictions on capital inflows and the economic activities such as trade and investment among the countries also increase integrations between equity markets.

\section{H1b: unidirectional volatility spillover between Asian countries' stock markets}

The unidirectional linkages in terms of volatility is observed to be flowing in the following markets: from the stock market of India to China, from the stock market of Sri Lanka to Japan, from the stock market of Hong Kong to India, from the stock market of Pakistan to Sri Lanka, from the stock market of Pakistan to Hong Kong, and from the stock market of Pakistan to Japan. The unidirectional shock spillover provides the knowledge about the shock that is produced in one market and is transmitted to the other markets while the shock-receiving market does not respond to the shock-sending market. The magnitude of the highest cross market shock spillover has been found from the stock market of Pakistan to Hong Kong $(-0.041)$ while the lowest has been found from the stock market of Hong Kong to Sri Lanka (-0.006). The stock markets of Sri Lanka and Pakistan has been found to have volatility spillover to most of the selected equity markets. The results of the study are consistent with Joshi (2011).

\section{Conclusions}

This study was an attempt to examine the volatility spillover dynamics between the selected Asian countries' stock markets for the period 4 January 1999 to 1 January 2014. The analyses were based on daily data to examine the daily shock spillover between the financial markets. The Asian countries considered for the analyses were Pakistan, India, Sri Lanka, China, Japan, and Hong Kong. The sample also constitutes a mixture of diverse mix countries. The stationarity of the variables was examined by using unit root analyses. The volatility transmission has been explored by using the GARCH model. The empirical results reveal significant return and volatility spillover between Asian countries' stock markets. The analyses reveal bidirectional return spillover between the 
stock markets of China and Japan only. The unidirectional transmission of return is observed to be flowing from Sri Lanka to India, China to Hong Kong, Hong Kong and China to Pakistan, and India to Japan and Hong Kong. The empirical evidence on bidirectional flow of volatility is found in the following countries: Hong Kong and Sri Lanka, China and Sri Lanka, and China and Japan. The unidirectional transmission of volatility from one country stock market to another country stock market is found to be flowing from India to China, Sri Lanka to Japan, Hong Kong to India, Pakistan to Sri Lanka, and Hong Kong to Japan. The analyses are evident of bidirectional transmission of return and volatility between China and Japan. Furthermore, the analyses show that none of the selected stock markets have volatility spillover to the stock market of Pakistan.

The results of the study have important implications for economic policy makers and investors. For economic policy makers, the information about volatility spillover between financial markets would be of greater interest for them for economic stability because financial market integrations imply financial sector integration, so the policy makers need to design such policies which would safeguard the financial sector from the international financial shocks. They would be able to predict any future crises, if they have some historical information about financial market integrations. Furthermore, they may be able to implement successful policies by having information about behavior of financial markets. The results of this study are also important for investors, who want to make efficient portfolios and make capital budgeting decisions in the selected markets. The institutional and individual investors can benefit from portfolio diversification by investing in non-correlated markets which will reduce their risk and enhance their returns. They may be able to prevent themselves from the financial crises of markets by investing in non-integrated markets.

Competing interests

The authors declare that they have no competing interests.

Authors' contributions

Al wrote the first and second sections of the article. $\mathrm{KJ}$ wrote the rest of the sections of the manuscript. Both authors have read and approved the final manuscript.

\section{Authors' information}

KJ has done Masters in Finance from Mohammad Ali Jinnah University, Islamabad, Pakistan. He is currently working as a visiting lecturer in the University of Malakand Pakistan.

Al has done Masters in Finance from Mohammad Ali Jinnah University, Islamabad, Pakistan. He is currently a doctoral student in the School of Accounting, Dongbei University of Finance and Economics, China.

Author details

${ }^{1}$ Department of Management Studies, University of Malakand, Chakdara, Pakistan. ${ }^{2}$ School of Accounting, Dongbei University of Finance and Economics, Dalian, China.

Received: 6 August 2015 Accepted: 3 March 2016

Published online: 04 April 2016

\section{References}

Baele L (2002) Volatility spillover effects in European equity markets: evidence from a regime switching model. Ghent University, Working Paper, 1-62.

Beirne J, Caporale GM, Ghattas MS, Spagnolo N (2009) Volatility spillovers and contagion from mature to emerging stock markets. Working Paper series 1113:1-48

Choo WC, Loo SC, Ling LB, Ung SN (2011) Return and volatility spillover between large and small stocks in Bursa Malaysia. Int J Busin Soc Sci 2:176-185

Chou RY, Lin JL, Wu CS (1999) Modeling the Taiwan stock market and international linkages. Pacif Econ Rev 4(3):305-320

Dickey DA, Fuller WA (1979) Distribution of the estimators for autoregressive time series with a unit root. J Amer stat asso 74(366a):427-431

Diebold FX, Yilmaz K (2009) Measuring financial asset return and volatility spillovers, with application to global equity markets. The Econ J 119(534):158-171 
Glezakos M, Merika A, Kaligosfiris H (2007) Interdependence of major world stock exchanges: how is the Athens Stock Exchange affected. Int Res J Finan Econ 7(1):24-39

Harris RD, Pisedtasalasai A (2006) Return and volatility spillovers between large and small stocks in the UK. J Busi Finan Acc 33(9-10):1556-1571

Hu JWS, Chen MY, Fok RC, Huang BN (1997) Causality in volatility and volatility spillover effects between US, Japan and four equity markets in the South China growth triangular. J Int Finan Mark, Inst Money 7(4):351-367

Jebran K (2014) Dynamic linkages between Asian countries stock markets: evidence from Karachi Stock Exchange. Res J Mang Sci 3(5):6-13

Joshi P (2011) Return and volatility spillovers among Asian stock markets. SAGE Open 1(1):2

Li H, Majerowska E (2008) Testing stock market linkages for Poland and Hungary: a multivariate GARCH approach. Res int Busin Finan 22(3):247-266

Markowitz H (1952) Portfolio selection. The j finan 7(1):77-91

Mukherjee KN, Mishra RK (2010) Stock market integration and volatility spillover: India and its major Asian counterparts. Res int Busin and Finan 24(2):235-251

$\mathrm{Ng} \mathrm{A} \mathrm{(2000)} \mathrm{Volatility} \mathrm{spillover} \mathrm{effects} \mathrm{from} \mathrm{Japan} \mathrm{and} \mathrm{the} \mathrm{US} \mathrm{to} \mathrm{the} \mathrm{Pacific-Basin.} \mathrm{J} \mathrm{int} \mathrm{money} \mathrm{finan} \mathrm{19(2):207-233}$

Phillips PC, Perron P (1988) Testing for a unit root in time series regression. Biomet 75(2):335-346

Sakthivel P, Kamaiah B (2011) Correlation and volatility transmission across international stock markets: a bivariate GARCH analysis. J App Res Finan Bi-Ann 3(2):270-278

Wagner N, Szimayer A (2004) Local and spillover shocks in implied market volatility: evidence for the US and Germany. Res int Busin Finan 18(3):237-251

Wang Y, Gunasekarage A, Power DM (2005) Return and volatility spillovers from developed to emerging capital markets: the case of South Asia. Contemp Stud Econ Finan Anal 86:139-166

Worthington A, Higgs H (2004) Transmission of equity returns and volatility in Asian developed and emerging markets: a multivariate GARCH analysis. Int J Finan Econ 9(1):71-80

Xiao L, Dhesi G (2010) Volatility spillover and time varying conditional correlation between the European and US stock markets. Glob Eco Finan J 3(2):148-164

Submit your manuscript to a SpringerOpen ${ }^{\circ}$ journal and benefit from:

- Convenient online submission

- Rigorous peer review

- Immediate publication on acceptance

- Open access: articles freely available online

- High visibility within the field

- Retaining the copyright to your article

Submit your next manuscript at $>$ springeropen.com 